\title{
Avaliação da acidez da dieta líquida ingerida pelos pacientes da Clínica de odontopediatria da Univali
}

\section{Assessment of the acidity in the liquid diet ingested by patients of the odontopediatric clinic at Univali}

\author{
Maria Mercês Aquino Gouveia Farias* \\ Jaqueline Salvalagio Marques ${ }^{* *}$ \\ Beatriz Helena Eger Schmitt ${ }^{* *}$ \\ Eliane Garcia da Silveira ${ }^{* * * *}$ \\ Silvana Marchiori de Araújo ${ }^{* * * *}$
}

\section{Resumo}

Objetivo: esta pesquisa objetivou avaliar a acidez da dieta líquida ingerida pelos pacientes da Clínica de odontopediatria da Univali. Materiais e método: caracteriza-se como um estudo descritivo, transversal, mediante levantamento de dados primários, seguido de uma fase laboratorial. A população alvo compreendeu 76 responsáveis pelas crianças atendidas na Clínica de odontopediatria da Univali no primeiro e no segundo semestres de 2012, constituindo uma amostra não probabilística obtida por conveniência. Na primeira etapa, os pais ou responsáveis responderam um questionário a respeito dos tipos de bebidas mais consumidas pelas crianças em cinco momentos do dia: café da manhã, almoço, jantar, lanches e bebida eleita para sanar a sede entre as refeições. Na segunda etapa, foram determinados o $\mathrm{pH}$ e a acidez titulável nas bebidas eleitas. Os dados foram apresentados de forma descritiva. Resultado: demonstrou-se que todas as bebidas dos grupos G-2 e G-3 apresentam potencial erosivo, por exibirem valores de $\mathrm{pH}$ inferiores a 5,5. As bebidas ácidas são consumidas principalmente no almoço $(85,52 \%)$ e no jantar $(64,47 \%)$ e os leites e derivados no café da manhã $(89,47 \%)$ e nos lanches (51,32\%). A água foi, para a maioria $(89,47 \%)$, a bebida de escolha para sanar a sede entre as refeições. Conclusão: com base nos da- dos, conclui-se que todas as bebidas dos grupos 2 (sucos industrializados, naturais e em pó) e 3 (refrigerantes) apresentam potencial erosivo, podendo contribuir para o desenvolvimento da erosão dental, especialmente nas crianças que utilizam essas bebidas como a primeira escolha para sanar a sede.

Palavras-chave: Erosão dentária. Hábitos alimentares. Acidez.

\section{Introdução}

O aumento da oferta, da procura e do consumo de produtos ácidos está fortemente associado ao risco de desenvolver lesões de erosão dental. Pesquisas recentes que investigaram esse problema entre crianças e adolescentes apontaram os hábitos alimentares como um dos principais fatores de risco para o desenvolvimento da erosão $0^{1-3}$.

A erosão dental é o desgaste químico provocado por ácidos extrínsecos (medicamentos, alimentos e bebidas ácidas), intrínsecos (vômitos) ou por substâncias quelantes, em superfícies livres de biofilme bacteriano ${ }^{4}$.

Mestre em odontopediatria, professora da disciplina de Odontopediatria do curso de graduação em Odontologia da Universidade do Vale de Itajaí (Univali). Acadêmica do curso de graduação em Odontologia da Universidade do Vale de Itajaí (Univali).

Mestre em odontopediatria, professora da disciplina de Odontopediatria do curso de graduação em Odontologia da Universidade do Vale de Itajaí (Univali). Mestre em odontopediatria, professora da disciplina de Odontopediatria do curso de graduação em Odontologia da Universidade do Vale de Itajaí (Univali). Doutora em odontopediatria, professora da disciplina de Odontopediatria do curso de graduação em Odontologia da Universidade do Vale de Itajaí (Univali) 
Dentre os diversos fatores associados à etiologia da erosão dental por causas extrínsecas, o consumo excessivo de alimentos e de bebidas ácidas tem um papel de destaque ${ }^{5}$. Nesse sentido, vários estudos tem se dedicado a analisar o potencial erosivo da dieta líquida ${ }^{6-11}$.

A instalação e a progressão da erosão dental dependem da interação de vários fatores, dentre os quais se destacam os químicos, os comportamentais e os biológicos ${ }^{12}$. Do ponto de vista físico-químico, o tipo de ácido, o $\mathrm{pH}$, a acidez titulável, o potencial quelante, a concentração de cálcio e de fosfato, a temperatura e a adesividade podem influenciar o potencial erosivo das bebidas ácidas. Individualmente, o pH, a acidez titulável e o conteúdo de cálcio são os parâmetros que melhor revelam a capacidade das bebidas em proporcionar a dissolução mineral da estrutura dental ${ }^{13}$. Em relação aos fatores comportamentais destacam-se os hábitos dietéticos e o estilo de vida. Quanto aos biológicos, as propriedades protetoras da saliva e a formação da película adquirida são os mais importantes ${ }^{14}$.

A análise e o aconselhamento dietético fazem parte da rotina do atendimento odontopediátrico. Esse momento permite ao profissional orientar a criança e o seu núcleo familiar sobre a relação entre uma alimentação saudável e a saúde oral e geral.

Dentro desse contexto, o objetivo deste estudo foi identificar as bebidas mais consumidas pelas crianças atendidas na Clínica de odontopediatria da Univali em sua rotina diária e, em sequência, mensurar a acidez das bebidas de maior consumo, para verificar se as bebidas consumidas pelas crianças expõem-nas ao risco de desenvolver lesões de erosão.

\section{Materiais e método}

Este projeto foi previamente encaminhado ao Comitê de Ética em Pesquisa da Univali e aprovado sob o parecer 10145 .

Esta investigação caracteriza-se como um estudo descritivo, do tipo transversal, mediante levantamento de dados primários, por meio de questionário, ao que se segue uma fase laboratorial para mensuração do $\mathrm{pH}$ e da acidez titulável das bebidas.

A população-alvo compreendeu 76 pais ou responsáveis pelas crianças atendidas na Clínica de odontopediatria da Univali no primeiro e no segundo semestres de 2012, constituindo uma amostra não probabilística obtida por conveniência, isso é, integraram a pesquisa todos que, por livre e espontânea vontade, aceitaram participar desta pesquisa, para tanto, assinando o Termo de Consentimento Livre e Esclarecido.

Na primeira etapa, os pais ou responsáveis pelas crianças responderam a um questionário contendo seis questões abertas a respeito dos tipos de bebidas mais consumidas pelas crianças em cinco momentos do dia: café da manhã, almoço, jantar, lanches e momentos intermediários de sede. Os líquidos foram agrupados da seguinte maneira: G1- leite e complementos; G2- sucos industrializados, naturais ou em pó; G3-refrigerantes; G4-nada ou água.

$\mathrm{Na}$ segunda etapa, as bebidas mais consumidas em cada grupo foram obtidas em supermercados. A mensuração do $\mathrm{pH}$ inicial foi feita em triplicata, através de uma média de 3 aferições para cada bebida. O Quadro 1 demonstra como as bebidas foram preparadas antes das aferições. Sob temperatura ambiente, cada bebida foi agitada manualmente por 15 segundos, coletando-se três amostras $(30 \mathrm{~mL})$ de cada uma. Para esses ensaios foi utilizado um potenciômetro e um eletrodo combinado de vidro (Tec-2 Tecnal) previamente calibrado com soluções-padrão pH 7,0 e pH 4,0, antes de cada leitura.

Quadro 1 - Forma de preparo das bebidas para a aferição do $\mathrm{pH}$ e da acidez titulável

\begin{tabular}{|c|c|}
\hline Grupos & Obtenção das amostras \\
\hline $\begin{array}{l}\text { G-1 } \\
\text { leite e } \\
\text { complementos }\end{array}$ & $\begin{array}{l}\text { - Após a preparação do café, } \\
\text { conforme instruções do } \\
\text { fabricante, esse foi misturado com } \\
\text { o leite numa proporção de } 1: 1 \text {. } \\
\text { - Para as preparações de } \\
\text { achocolatado com leite, foi } \\
\text { obedecida a recomendação do } \\
\text { fabricante. }\end{array}$ \\
\hline $\begin{array}{l}\text { G-2 } \\
\text { sucos } \\
\text { industrializados, } \\
\text { naturais e em pó }\end{array}$ & $\begin{array}{l}\text { - Nos sucos disponíveis em caixa, } \\
\text { foi coletado o volume necessário } \\
\text { da bebida pronta. } \\
\text { - Como suco natural de laranja foi } \\
\text { considerado o suco da fruta sem } \\
\text { diluições. } \\
\text { - O suco natural de acerola foi } \\
\text { diluído em água; } \\
\text { - Os sucos em pó foram } \\
\text { diluídos conforme instruções do } \\
\text { fabricante. }\end{array}$ \\
\hline $\begin{array}{l}\text { G-3 } \\
\text { refrigerantes }\end{array}$ & $\begin{array}{l}\text { - Coletado o volume necessário } \\
\text { da bebida pronta. }\end{array}$ \\
\hline $\begin{array}{l}\text { G-4 } \\
\text { nada ou água }\end{array}$ & $\begin{array}{l}\text { - Coletado o volume necessário } \\
\text { da bebida pronta. }\end{array}$ \\
\hline
\end{tabular}

As bebidas que apresentaram $\mathrm{pH}$ inferior a 5,5. foram classificadas como potencialmente erosivas. Nessas foi mensurada a acidez titulável em triplicata, coletando-se $50 \mathrm{~mL}$ de cada bebida para as três titulações. Para cada titulação, foi adicionada, com o auxílio de uma pipeta, alíquotas de $100 \mu \mathrm{L}$ de $\mathrm{NaOH} 1 \mathrm{~N}$, sob agitação constante (Agitador Magnético Fisaton), medindo-se subsequentemente o $\mathrm{pH}$, até se alcançar $\mathrm{pH} 5,5$.

Os dados da primeira etapa foram tabulados segundo os quatro grupos: G1- leite e complementos; G2 - sucos industrializados, naturais ou em pó; G3 - refrigerantes; G4-nada ou água. Com o auxílio do programa Microsoft Office Excel for Mac 2011, foram apresentados de forma descritiva e por meio de tabelas que se demonstram o cálculo das frequências relativas. 
Os dados da segunda etapa foram apresentados a partir do cálculo das médias do $\mathrm{pH}$ e da acidez titulável.

Por meio do presente estudo, os participantes foram beneficiados com informações apresentadas em um folheto informativo a respeito da erosão dental e sua relação com o consumo de bebidas ácidas, o qual foi distribuído após a devolução do questionário preenchido.

\section{Resultados}

As bebidas ácidas são consumidas principalmente no almoço $(85,52 \%)$ e no jantar $(64,47 \%)$ e os leites e complementos são prefereência no café da manhã $(89,47 \%)$ e nos lanches $(51,32 \%)$. A água foi para a maioria $(89,47 \%)$ a bebida de escolha para sanar a sede entre as refeições.

As Tabelas de 1 a 5 demonstram a distribuição dos grupos nos cinco momentos de ingestão diária.

Tabela 1 - Distribuição da frequência relativa das bebidas consumidas no café da manhã, segundo os grupos:

\begin{tabular}{l|r|r}
\multicolumn{1}{c|}{ Grupos } & $\mathrm{N}$ & \multicolumn{1}{c}{$\%$} \\
\hline G-1 leite e complementos & 68 & 89,47 \\
\hline G-2 sucos industrializados, naturais e em pó & 2 & 2,63 \\
\hline G-3 refrigerantes & 0 & 0 \\
\hline G-4 nada ou água & 6 & 7,89 \\
\hline Total & 76 & 100 \\
\hline
\end{tabular}

Fonte: dados da pesquisa.

Tabela 2 - Distribuição da frequência relativa das bebidas consumidas no almoço, segundo os grupos:

\begin{tabular}{l|r|r}
\multicolumn{1}{c|}{ Grupos } & N & $\%$ \\
\hline G-1 leite e complementos & 0 & 0,00 \\
\hline G-2 sucos industrializados, naturais e em pó & 56 & 73,68 \\
\hline G-3 refrigerantes & 9 & 11,84 \\
\hline G-4 nada ou água & 11 & 14,47 \\
\hline Total & 76 & 100 \\
\hline
\end{tabular}

Fonte: dados da pesquisa.

Tabela 3 - Distribuição da frequência relativa das bebidas consumidas no lanche, segundo os grupos:

\begin{tabular}{l|r|r}
\multicolumn{1}{c|}{ Grupos } & $\mathrm{N}$ & $\%$ \\
\hline G-1 leite e complementos & 39 & 51,32 \\
\hline G-2 sucos industrializados, naturais e em pó & 14 & 18,42 \\
\hline G-3 refrigerantes & 0 & 0 \\
\hline G-4 nada ou água & 23 & 30,26 \\
\hline Total & 76 & 100 \\
\hline
\end{tabular}

Fonte: dados da pesquisa.
Tabela 4 - Distribuição da frequência relativa das bebidas consumidas no jantar, segundo os grupos:

\begin{tabular}{l|r|r}
\multicolumn{1}{c|}{ Grupos } & N & \multicolumn{1}{c}{$\%$} \\
\hline G-1 leite e complementos & 13 & 17,11 \\
\hline G-2 sucos industrializados, naturais e em pó & 44 & 57,89 \\
\hline G-3 refrigerantes & 5 & 6,58 \\
\hline G-4 nada ou água & 14 & 18,42 \\
\hline Total & 76 & 100 \\
\hline
\end{tabular}

Fonte: dados da pesquisa.

Tabela 5 - Distribuição da frequência relativa das bebidas consumidas em momentos intermediários de sede, segundo os grupos:

\begin{tabular}{l|r|c}
\multicolumn{1}{c|}{ Grupos } & \multicolumn{1}{c}{ N } & \multicolumn{1}{c}{$\%$} \\
\hline G-1 leite e complementos & 0 & 0,00 \\
\hline G-2 sucos industrializados, naturais e em pó & 8 & 10,53 \\
\hline G-3 refrigerantes & 0 & 0,00 \\
\hline G-4 nada ou água & 68 & 89,47 \\
\hline Total & 76 & 100 \\
\hline
\end{tabular}

Fonte: dados da pesquisa.

O Quadro 2 expõe os alimentos constituintes da dieta líquida mais consumidos pelos pacientes das Clínicas de odontopediatria da Univali, em cada um dos grupos, durante as refeições diárias: café da manhã, almoço, jantar, lanches e, nos espaços entre essas, para sanar a sede. 
Quadro 2 - Apresentação das bebidas consumidas durante as refeições diárias, seguidas de seus respectivos pH(s) e de sua acidez titulável

\begin{tabular}{|c|c|c|c|}
\hline Grupos & Bebidas & Média do pH & Média do volume de $\mathrm{NaOH}(\mu \mathrm{L})$ \\
\hline G-1 & $\begin{array}{l}\text { Café Caboclo }{ }^{\circledR}+\text { leite Tirol }^{\circledR} \\
\text { Café Melita }^{\circledR}+{\text { leite } \text { Tirol }^{\circledR}} \\
\text { Leite Tirol } \\
\text { Leite Tirol }\end{array}$ & $\begin{array}{l}6,46 \\
6,54 \\
6,50 \\
6,54\end{array}$ & \\
\hline G-2 & $\begin{array}{l}\text { Suco Ades laranja }{ }^{\circledR} \\
\text { Suco Ades maçã } \\
\text { Suco em pó Trink laranja }{ }^{\circledR} \\
\text { Suco em pó Tang uva }{ }^{\circledR} \\
\text { Suco em pó Tang abacaxi }{ }^{\circledR} \\
\text { Suco em pó Tang Laranja }{ }^{\circledR} \\
\text { Suco natural laranja } \\
\text { Suco natural acerola }\end{array}$ & $\begin{array}{l}3,85 \\
3,89 \\
2,72 \\
3,39 \\
3,70 \\
3,36 \\
3,38 \\
3,37\end{array}$ & $\begin{array}{r}900 \\
833 \\
2233 \\
1800 \\
1250 \\
1800 \\
4567 \\
1133\end{array}$ \\
\hline G-3 & $\begin{array}{l}\text { Guaraná Antártica }{ }^{\circledR} \\
\text { Coca-Cola }^{\circledR} \\
\text { Max Limão }\end{array}$ & $\begin{array}{l}3,25 \\
2,55 \\
2,91\end{array}$ & $\begin{array}{r}800 \\
600 \\
1800\end{array}$ \\
\hline G-4 & Água & 6,78 & \\
\hline
\end{tabular}

\section{Discussão}

A dieta ácida inclui os ácidos cítrico, fosfórico, fumárico, ascórbico, málico, tartárico, oxálico e carbônico, presentes em frutas, sucos de frutas, balas, refrigerantes e vinagres, e constitui uma das principais causas da erosão dental ${ }^{15}$. Dentre os diveros tipos de bebidas analisadas, destacaram-se como potencialmente erosivas as listadas nos grupos 2 e 3, por apresentarem valores de $\mathrm{pH}$ inferiores a 5,5 , valor crítico para a dissolução do esmalte dentário ${ }^{13}$. Esse achado corrobora com diversos estudos que confirmam a acidez de sucos de fruta (industrializados e naturais) e refrigerantes ${ }^{6,8,10,11,16,17}$.

Embora as bebidas ácidas façam parte da dieta líquida da amostra estudada, foram predominantes apenas no almoço e no jantar. Esse resultado, relacionado ao momento de ingestão, está de acordo com a recomendação de restringir o consumo de bebidas ácidas às refeições principais, no intuito de prevenir erosão dental ${ }^{5,18,19}$. Essa redução pode ser considerada como um fator que reduz o risco de desenvolvimentodas lesões.

Dentre as bebidas apresentadas no G-2, observa-se o predomínio dos sucos artificiais em pó. Os preparados artificiais sólidos para refresco são parte integrante da rotina de consumidores brasileiros, uma vez que, são de fácil preparo, alto rendimento e baixo custo, o que os torna muito atrativos para as populações de baixa renda ${ }^{20}$. Quanto ao potencial erosivo dessas bebidas, foi observado, em estudo prévio, uma acidez titulável significantemente mais elevada do que a de bebidas isotônicas, refrigerantes e chás ${ }^{21}$. No presente estudo, os sucos em pó também apresentaram acidez titulável mais alta do que a dos sucos industrailizados disponíveis em caixa e do que a dos refrigerantes.
É importante ressaltar que os sucos industrializados comumente apresentam vários componentes químicos, entre eles alguns ácidos atuando como anti-oxidantes, tal como o ácido ascórbico e os reguladores de $\mathrm{pH}$, por exemplo, o ácido cítrico. A presença desses componentes pode ter relação com o desenvolvimento de lesões de erosão dental e com reações alérgicas, o que direciona para eleger o consumo de sucos naturais como o mais adquado à asúde bucal ${ }^{22,23}$. Além disso, o ácido cítrico é um ácido orgânico com propriedades erosivas acentuadas que provoca a queda do $\mathrm{pH}$ salivar, desencadeando a dissolução do esmalte. $O$ processo de desmineralização pode se agravar, pois, o ânion citrato age como uma substância quelante de íons de cálcio, aumentando a desmineralização do esmalte dentário, por exacerbar a condição local de subsaturação desse íon. Disso resulta um efeito desmineralizante, mesmo após o pH ter alcançado, na superfície dentária, a neutralidade ${ }^{24}$.

Nesse sentido, deve-se privilegiar frutas, pois são uma importante fonte de nutrientes como vitaminas, fibras e outros fitoquímicos que protegem contra doenças e parecem ser menos causadores de erosão do que os sucos de frutas ${ }^{18}$. Os guias alimentares brasileiros relacionados à saúde bucal incentivam o consumo de frutas e de legumes e desaconselham o consumo de bebidas artificiais ${ }^{25,26}$. É relevante destacar que, nos casos em que a criança já apresente lesões de erosão, deve-se priorizar o consumo de frutas não cítricas ${ }^{5,19}$. $\mathrm{O}$ ácido cítrico é o tipo de ácido predominante nas frutas como a laranja, que se destacou nesta pesquisa, por apresentar a elevada acidez titulável, a mesma situação observada no estudo de Farias et al. ${ }^{6}(2000)$.

Café sem misturas não foi citado em nenhum dos momentos de ingestão, o que pode ser considerado um fator positivo, pois estudo anterior demonstrou 
a acidez dessa bebida ${ }^{7}$. No presente estudo, o acréscimo de leite parece ter elevado o $\mathrm{pH}$ das bebidas.

Leite e complementos foram as bebidas mais mencionadas no café da manhã e no lanche. Reconhecemos esse achado como uma característica positiva para a prevenção da erosão, uma vez que, o consumo de leite e derivados também representa uma medida de prevenção $0^{19}$.

Por um lado, a grande maioria utiliza água para sanar a sede $(89,47 \%)$. Por outro, $10,53 \%$ das crianças, segundo seus responsáveis, elegem os sucos de fruta como as bebidas de primeira escolha para esse fim, o que representa um dos principais fatores de risco para o desenvolvimento de lesões de erosão $0^{5,19}$. Fato observado por O'Sullivan e Curzon ${ }^{27}$ (2000), que, ao compararem fatores dietéticos em crianças com e sem erosão dental, mostraram que as crianças com erosão dental bebiam significantemente mais bebidas ácidas e menos água do que aquelas que não apresentavam lesões. Isso porque a frequência de ingestão potencializa o risco de desenvolver lesões de erosão ${ }^{5,28,29}$.

Além de fatores físico-químicos, o desgaste erosivo sofre influência de fatores comportamentais (hábitos de higiene, hábitos de ingestão de alimentos e bebidas, prática de esportes), biológicos (saliva, película adquirida) e socioeconômicos ${ }^{5}$. A interferência desses justifica a maior ou a menor suscetibilidade de alguns indivíduos a desenvolver lesões de erosão ${ }^{14}$.

O entendimento do potencial erosivo da dieta é apenas parte integrante de um conjunto de conhecimentos que convergem para a prevenção da erosão dental, do qual participam uma série de medidas que permitem ao cirurgião-dentista orientar seus pacientes durante a prática clínica, são elas: orientar o consumo racional de bebidas ácidas, preferencialmente geladas e durante as principais refeições; orientar o consumo de água como o líquido de primeira escolha para sanar a sede; estimular o consumo de frutas frescas como parte de uma dieta saudável; desaconselhar o consumo de bebidas ácidas em mamadeiras e durante o sono; estimular o uso de copos e canudos; evitar a escovação dos dentes logo após a ingestão de bebidas ácidas; recomendar o uso de dentifrícios com baixa abrasividade. A presença dessas condutas na rotina diária contribui para prevenção da erosão dental ${ }^{5,18,19}$.

\section{Conclusão}

Todas as bebidas listadas nos Grupos 2 (sucos industrializados, naturais e em pó) e 3 (refrigerantes) apresentam potencial erosivo, podendo contribuir para o desenvolvimento de lesões de erosão, especialmente nas crianças que as utilizam como a primeira escolha para sanar a sede, devido ao fato de estarem ingerindo ácidos nocivos.

\section{Agradecimentos}

Ao Programa de Iniciação Científica Artigo170/ Governo do Estado de Santa Catarina/ Pró-Reitoria de Pesquisa, Pós-Graduação, Extensão e Cultura da Universidade do Vale do Itajaí - Univali, que financiou a pesquisa.

\section{Abstract}

Objective: This research aimed to assess the acidity of the liquid diet ingested by the patients of the UNIVALI pedodontics. Materials and method: It is characterized as a descriptive, transversal study, by means of a primary data collection, followed by a laboratory phase. The population comprised 76 responsible for the children attended in the pedodontics of UNIVALI in the first and second semester of 2012, constituting a non-probabilistic sample obtained by convenience. In the first stage, the parents or guardians answered the questionnaire regarding the types of beverages most consumed by children at 5 moments of the day: breakfast, lunch, dinner, snacks and drinks elected for quenching thirst in between meals. The liquids were grouped into: G1milk and add-ons; G2- industrialized juices, natural or as powder; G3- soft drinks; G4- nothing or water. On the second stage, the $\mathrm{pH}$ and titratable acidity were determined in the elected drinks. The data were presented descriptive form. Results: It was demonstrated that all drinks of groups G-2 and G-3 present erosive potential, since they presented $\mathrm{pH}$ values under 5.5. The acidic drinks are consumed mostly at lunch $(85.52 \%)$ and dinner $(64.47 \%)$ and the milks and derivatives for breakfast (89.47\%) and snacks (51.32\%). For most people $(89.47 \%)$, water was chosen for quenching thirst in between meals. Conclusion: It is concluded that all drinks from groups 2 and 3 present erosive potential and could contribute to the development of erosion damages, especially in children who use them as the first choice to quench thirst.

Keywords: Dental erosion. Eating habits. Acidity.

\section{Referências}

1. Correr GM; Alonso RC; Correa MA; Campos EA; Baratto-Filho F; Puppin-Rontani RM. Influence of diet and salivary characteristics on the prevalence of dental erosion among 12-year-old schoolchildren. J Dent Child 2009; 76(3):181-7.

2. Correa MSNP; Corrêa FNP; Correa JPNP; Murakami C; Mendes FM. Prevalence and associated factors of dental erosion in children and adolescents of a private dental practice. Int J Paediatr Dent 2011; 21:451-8.

3. Murakami C; Oliveira LB; Sheiram A; Corrêa MSNP; Haddad AE; Bonecker M. Risk indicators for erosive tooth wear in brazilian preschool children. Caries Res 2011; 45:121-9.

4. Gans C. Definition of erosion and links to tooth wear. Monogr Oral Sci 2006; 20:9-16.

5. Magalhães AC; Wiegand A; Rios D; Honório HM; Buzalaf MAR. Insights into preventive measures for dental erosion. J Appl Oral Sci 2009; 17(2):75-86.

6. Farias MMAG; Tames DR; Ferreira R; Bahi FC; Morreto J. Propriedades erosivas de sucos de frutas industrializados 
recomendados como suplemento alimentar para crianças. J Bras Odontoped Odontol Bebê 2000; 3(12):111-7.

7. Dantas RVF, Valença AMG, Claudino LV, Lima AL, Carvajal JCL, Costa GF. Características físico-químicas da dieta líquida cafeinada. Pesq Bras Odontoped Clin Integr, 2008; 8(3):333-6.

8. Farias MMAG; Bernardi M; Silva Neto R; Tames DR; Silveira EG; Bottan ER. Avaliação de propriedades erosivas de bebidas industrializadas acrescidas de soja em sua composição. Pesq Bras Odontoped Clin Integr 2009; 9(3):277-81.

9. Lodi CS, Sassaki KT, Fraiz FC, Delbem AC, Martinhon CC. Evaluation of some properties of fermented milk beverages that affect the demineralization of dental enamel. Braz Oral Res 2010; 24:95-101.

10. Farias MMAG; Ozelame SB; Schmitt BHE; Capristano DF; Silveira EG. Avaliação da acidez de diversas marcas de leite fermentado disponíveis comercialmente, Pesq Bras odontopediatria Clin Integr 2012; 12:451-5.

11. Silva JG; MMAG Farias; Silveira EG; Schmitt BHE; Araújo SM. Mensuração da acidez de bebidas não lácteas destinadas ao público infantil. Rev Odontol UNESP 2012; 41:76-80.

12. Lussi A. Erosive tooth wear- a multifactorial condition of growing concern and increasing knowledge. Monogr Oral Sci 2006; 20:1-8.

13. Furtado JR; Freire VC; Messias DCF; Turssi CP. Aspectos físico-químicos relacionados ao potencial erosivo de bebidas ácidas. Rev Fac Odontal Univ Passo Fundo 2010; 15(3):325-30.

14. Zero DT; Lussi A. Erosion - chemical and biological factors of importance to the dental practitioner. Int Dent J 2005; $55(4): 285-9$

15. Moynihan PJ. The role of diet and nutrition in the etiologia and prevention of oral diseases. Bull of World Health Organ 2005; 83(9):694-9.

16. Sales-Peres SH; Magalhães AC; Machado AM; Buzalaf MAR. Evaluation of the erosive potential of soft drinks. Eur J Dent 2007; 1:10-3.

17. Zandim DL; Corrêa FO; Rossa Júnior C; Sampaio JE. In vitro evaluation of the effect of natural orinage juices on dentin morphology. Braz Oral Res 2008; 22(1):176-83.

18. Aud S, Moynihan P. Diet and dental erosion. Quintessence Int 2007; 37(2):130-3.

19. Fox C. Evidence summary: how can dietary advice to prevent dental erosion be effectively delivered in UK general dental practice? Brit Dent J 2010; 208(5):217-8.

20. Instituto nacional de metrologia, Qualidade e Tecnologia Inmetro. Preparado sólido artificial para refresco (pó para refresco). Disponível em: <http://www.inmetro.gov.br/consumidor/produtos/refresco.asp>. Acesso em: 22 fev. 2013.

21. Corso S; Padilha DMP; Corso AC; Hugo FN. Avaliação do potencial erosivo de sucos de frutas artificiais em pó, refrigerantes, isotônicos e chás enlatados disponíveis comercialmente no Brasil. Rev Fac Odontal Univ Passo Fundo 2006; 11(1):45-50.

22. Touyz ZG. The acidity $(\mathrm{pH})$ and buffering capacity of canadian fruit juice and dental implications. J Can Dent Assoc 1994; 60(5):454-8.

23. Oliveira CH; Benotti RS; Quagliara PC; Rebechi M. Substâncias químicas presentes em sucos de fruta em pó comercializados no Brasil. Rev Bras Alerg Imuno Patol 2006; 29(3):127-32.

24. Feathertone JDB; LUSSI A. Undrestanding the chemistry of dental erosion. Monogr Oral Sci 2006; 20:66-76

25. Brasil. Ministério da Saúde. Secretaria de Assistência à saúde. Coordenação Geral da Política de Alimentação e Nutrição, Departamento de Atenção Básica, Secretaria de Assistência à Saúde, Ministério da Saúde. Guia alimentar para a população brasileira: promovendo a alimentação saudável. Brasília: Ministério da Saúde; 2006. Disponível em: <http://dtr2001.saude.gov.br/editora/produtos/livros/ pdf/05_1109_M.pdf >. Acesso em: 20 ago. 2013.

26. Freire MCM; Balbo PL; Amador MA; Sardinha LMV. Guias alimentares para a população brasileira: implicações para a Política nacional de Saúde Bucal. Cad. Saúde Pública 2012; 28, sup. S20-S29.

27. O'sullivan EA; Curzon ME. A comparison of acidic dietary factors in children with and without dental erosion. ASDC J Dent Child 2000; 67(3):186-92.

28. Dugmore CR; Rock WP. A multifactorial analisys of factors associated with dental erosion. Br Dent J 2004; 196:283-6.

29. Bassiouny MA. Clinical observation of dental erosion associeted with citrus diet and intake methods. Gen Dent 2014; 62(1):49-55.

Endereço para correspondência:

Maria Mercês Aquino Gouveia Farias

Rua Bartolomeu de Gusmão, 209, Carianos

88047-520 Florianópolis/SC

Fone: (048)-3236-1192/ 48-9622-1645

E-mail: mercesfarias@gmail.com; mercesfarias@univali.br.

Recebido: 04 / 12/2013. Aceito: 05/05/2014. 